\title{
ORIGINAL

\section{Correlation of Ki67 Expression with Hormone Receptors, Human Epidermal Growth Factor Receptor-2 (HER-2) Status, P53 Mutation and Clinicopathological Characteristics in Pathologic Specimens of Breast Cancer Patients}

Seyed Abbas Mirmalek ${ }^{1}$,Maedeh Ghorbani ${ }^{1}$, Ala Gholamrezaei Boushehrinejad ${ }^{2}$, Masoud Salehi ${ }^{3}$, Seyed Alireza Salimi-Tabatabaee ${ }^{4 凶}$, Hoda Aryan ${ }^{4}$

Department of Surgery, Islamic Azad University, Tehran Medical Sciences Branch, Tehran, Iran

${ }^{2}$ Students' Research Committee, Islamic Azad University, Tehran Medical Sciences Branch, Tehran, Iran

${ }^{3}$ Department of Biostatistics, Faculty of Management and Medical Informatics, Tehran University of Medical Sciences, Tehran, Iran

${ }^{4}$ Young Researchers and Elite Club, Islamic Azad University, Tehran Medical Sciences Branch, Tehran, Iran

\section{Abstract}

Background: Breast cancer is the main cause of cancer in women and the second cause of malignancy deaths. Ki-67 is one of the molecular markers used to evaluate cancer prognosis along with other factors such as age, tumor size, lymph node involvement, estrogen receptor (ER), progesterone receptor (PR), P53, human epidermal growth factor receptor-2 (HER-2), histological and nuclear grades. This study was aimed to evaluate the correlation of KI-67 expression with some biomarkers and clinico-pathological characteristics in breast cancer patients. Materials and Methods: A total of 513 cases (all female) aged 40- 80 years, were randomly selected from patients who were admitted in two centers affiliated with Tehran University of Medical Sciences (Buo-alli and Kasra hospitals) over a 7-year period (2010-2015). Assessment of tumors for HER-2, P53, ER PR, pathological type and histologic grade was performed. Ki-67 labelling index (Ki-67LI) was defined as the percentage of MIB1-positive cells among a total number of 1,000 malignant cells at high-power magnification $(\times 400)$.Results: Our study showed that age, ER and PR status were negatively correlated with Ki-67LI $(\mathrm{P}<0.05)$. Moreover, number of lymph nodes involved, HER-2, P53 and nuclear grades had a positive correlation with Ki67LI $(\mathrm{P}<0.05)$, whereas, tumor size and histological grade showed no significant correlation with Ki-67LI ( $\mathrm{P}=0.195$ and $\mathrm{P}=0.721$, respectively). Conclusion: Results of our study and other studies confirm that the expression of Ki-67 is significantly associated with ER, PR, HER-2 and P53 status. On the other hand, Ki-67 relationship with clinical characteristics such as age, tumor size and lymph node metastasis is not completely established and needs further research. [GMJ.2016;5(2):90-97]

Keywords:Breast Cancer; Ki-67; Estrogen Receptor; Progesterone Receptor; P53; Human Epidermal Growth Factor Receptor-2

\section{GMJ}

o2016 Galen Medical Journal

Fax: +98 7312227091

PO Box 7461686688

Email:info@gmj.ir

\author{
Correspondence to: \\ Seyed Alireza Salimi-Tabatabaee, Young Researchers \\ and Elite Club, Islamic Azad University, Tehran Medical \\ Sciences Branch, Tehran, Iran \\ Telephone Number: +9821-22006660 \\ Email Address: sartmed@gmail.com
}




\section{Introduction}

$\mathrm{B}$ reast cancer is a major public health issue and chief cause of cancer and cancerrelated mortality in women in Iran and many other parts of the world [1]. It is also the fifth cause of death in females in Iran [2]. Incidence of breast cancer varies around the world, it is more common in wealthy countries due to higher existence of risk factors such as higher age at first pregnancy, high calorie intake, sedentary lifestyle and the use of hormonal contraceptives [3,4]. Breast cancer prognosis is worse in less wealthy countries and in patients with lower income or educational level [4]. Although, it is of lowest incident in Asian countries; this rate is rising [5]. Mean age of breast cancer in Iran is 49 years old, whereas its mean age in western countries is 10 years older [6,7].

Age, tumor size, lymph node involvement, histological and nuclear grades of tumor are some of the prognostic factors for breast cancer [8]. In the past years, molecular research has allowed using different molecular markers including estrogen and progesterone receptors (ER and PR), human epidermal growth factor 2 (HER-2), P53 and recently added Ki-67 to predict the disease outcome. Expression of these markers impact the course of disease and treatment plan, since tumors with positive ER and PR status correspond better to hormone therapy and positive HER-2 tumors can be treated with Trastuzumab [9-10].

Ki-67 antigen, originally found by Gredes et al. [11], is involved in the initial steps of polymerase I dependent ribosomal RNA production [12]. Cells express this antigen during all cell-cycle phases except G0 (the resting phase) [13]. Ki-67 levels are highest in early mitosis; in later mitotic phases (anaphase and telophase), its levels sharply decrease [14]. $\mathrm{Ki}-67$ is associated with mitotic activity of the tissue, thus it correlates with mitotic index and because Ki-67 can be detected easier than mitotic index, it is thought to be a rather superior prognostic marker [15]. Trihia et al. used Ki-67 as an alternative for mitotic index in Nottingham grade and produced Nottingham/Ki-67 grade, and when it was evaluated for prognostic significance, it was similar to
Bloom-Richardson grade and Nottingham grade [16]. Weidnet et al. measured Ki-67 using MIB-1 antibody on paraffin embedded breast carcinoma samples and concluded that Ki-67 strongly correlates with both mitotic figure count and tumor grade [17]. Ki-67 is often measured on paraffin embedded sections using the MIB-1 antibody-based on percentage of tumor cells stained by the antibody. Normal breast tissue can express Ki-67 less than $3 \%[18]$.

$\mathrm{Ki}-67$ is studied mainly for its prognostic role in breast cancer; however, research continues to find other roles such as predicting the outcome of certain treatments, or identifying patients eligible for a certain adjuvant-therapy regime. A study on 3652 breast cancer patients in Japan revealed that higher Ki-67 profile significantly correlated with higher grade of malignancy, lower disease-free survival and overall survival, poorer prognosis and early recurrence [19]. A meta-analysis of 46 studies confirmed that Ki-67 was positivity associated with higher relapse and worse survival in breast cancer patients [20]. From 105 triple negative (ER, PR and HER2 negative) breast cancer patients under treatment of Doxorubicin and Docetaxel, those with higher Ki-67 $(\geq 10 \%)$ responded better to treatment, but had lower relapse-free survival and overall survival [21]. Another study demonstrated that Ki-67 improved the prediction of treatment response and prognosis in 552 breast cancer patients receiving neoadjuvant treatment, as mean Ki-67 values in patients with a pathological complete response were higher than patients without a complete response [22]. Considering the importance of $\mathrm{Ki}-67$ in breast cancer, this study was aimed to evaluate the correlation of KI-67 expression with some biomarkers and clinicopathological characteristics in breast cancer patients.

\section{Materials and Methods}

\section{Patients and Tumor Samples}

This was a cross-sectional study done on female patients older than 18 years referring to Buali or Kasra hospitals in Tehran, Iran between 2010 and 2015 for breast biopsy or surgery, and were diagnosed with breast can- 
cer in their pathology report. Total number of patients was 526 from whom 9 were males, 3 had bilateral tumor and one patient had a history of left mastectomy despite present tumor in right breast; these were excluded and the remainder of 513 patients entered the study. No calculation of sample size was done, and all qualified patients entered the study.

\section{Clinicopathological Features}

Data regarding age, tumor size, lymph node involvement, nuclear grade and histological grade were extracted from patients' records.

\section{Immunohistochemistry (IHC) Assessment}

All samples were evaluated by (IHC) staining under the direct supervision of at least two pathology academics.

3.1. Assessment of Ki-67

Formalin-fixed paraffin tissue sections (FFSs, $4 \mu \mathrm{m}$ ) mounted on Superfrost slides (Surgipath) were IHC stained, by using the standard streptavidin-biotin complex method, as previously described [23]. Microwave-assisted heat-induced retrieval method for antigen epitopes was performed in citrate buffer, at $\mathrm{pH}$ 6.0 for 20 minutes. Endogenous peroxidase activity was blocked by incubation in a $0.3 \%$ hydrogen peroxide in methanol buffer for 10 minutes. Nonspecific binding of primary antibody was blocked by using normal swine serum (NSS, in Tris-buffered saline (TBS) (1:5), $100 \mu \mathrm{l} /$ slide) for 10 minutes of incubation. Primary mouse monoclonal anti-Ki-67 antibody (MIB1 clone, product M7240; Dako, Glostrup, Denmark), diluted 1:100 (optimum working dilution) in NSS/TBS, was applied to each slide and incubated for 60 minutes at room temperature. Slides were then rinsed in TBS before staining with a streptavidin-biotin three-stage technique, with Dako Strept ABC complex/HRP Duet kit (Dako, K492) according to manufacturer's guidelines. For reaction visualization, 3-3 diaminobenzidine tetrahydrochloride (Dako liquid DAB Plus, K3468) was used as chromogen. The sections were counterstained with Mayer hematoxylin (Dako, AR106). Human tonsil sections were used as positive control, whereas negative control was performed by replacing the primary antibody by TBS.

\subsection{Ki67 Scoring}

Immunostaining was quantitatively evaluated by using light microscopy, in which the entire section was scanned at low-power magnification $(\times 100)$ to determine areas with the largest number of positive nuclei (hot spot) within the invasive component [23]. These were usually found at the periphery of tumors and were easier to identify than the mitotic figure hot spots. Ki-67 labeling index (Ki-67LI) was expressed as the percentage of MIB1-positive cells among a total number of 1,000 malignant cells at high-power magnification $(\times 400)$.

3.3. Determining HER-2 Status

HER-2 status was determined by means of IHC using Dako Hercep Test (Dako, Copenhagen, Denmark) and scored with Dako scoring system [9]. Only patients who had weak-to-moderate staining of the entire tumor-cell membrane for HER-2 (referred to as a score of $2+$ ) or more than moderate staining (referred to as a score of $3+$ ) in more than 10 percent of tumor cells on IHC analysis were eligible for the study.

3.4. Determining ER and PR Status

ER and PR status were determined with a modified avidin-biotin (ABC) immunoperoxidase method according to standard protocols (Vector Laboratories, Burlingame, CA). 3,3'-diaminobenzidine was used as chromogen. The immunostaining results for ER and PR were assessed semi-quantitatively and reported as positive if more than $5 \%$ of cells were immunostained in a tumor.

3.5. Determining P53 Overexpression

P53 overexpression was defined as more than $50 \%$ of the cells with strong nuclear staining as previously described [9].

\section{Statistical Analysis}

Due to normal distribution of selected variables evaluated by Kolmogorov-Smirnov test, we used simple linear regression model and Pearson correlation coefficient to evaluate the association between tumor size, number of involved lymph nodes, patients' age, histological grade, nuclear grade, ER, PR,P53 and HER-2 with Ki-67LI. Data was analyzed using SPSS version 20; P-values smaller than 0.05 were defined as significant. 


\section{Results}

Mean age of patients enrolled in this study was $52.8 \pm 11.71$ years. Moreover, maximum and minimum tumor sizes were $17 \mathrm{~cm}$ and $0.3 \mathrm{~cm}$, respectively, and mean tumor size was $2.9 \pm 1.77 \mathrm{~cm}$. We distributed patients according to their age into 6 groups. Most patients were in 40-50 years range, mean expression of Ki-67LI was measured for each group; patients aged 30-40 years had the highest mean Ki-67LI (34.17\%) and patients between 60-70 years old had the lowest mean Ki-67LI (27.22\%). Most of the cases had a tumor size between $1 \mathrm{~cm}$ and $3 \mathrm{~cm}(64.33 \%)$, mean Ki-67LI was highest in tumors between $5 \mathrm{~cm}$ and $7 \mathrm{~cm}(35.09 \%)$ and lowest in lower than $1 \mathrm{~cm}$ tumors $(27.93 \%)$, considering the reported tumor sizes. Lymph node involvement was not observed in $36.65 \%$ of patients, moreover, mean Ki-67LI was maximal in patients which had 7 to 9 of their lymph nodes involved. Histological grade was reported using Scarff-Bloom-Richardson grading system, better differentiated tumors have lower histological grade. More than half of subjects $(54.58 \%)$ had a histological grade of 2 and mean Ki-67LI increased along with histological grade, with Ki-67LI of $36.52 \%$ in grade 3 . Sixty-three point ninety-four percent of patients had a nuclear grade of 0 and patients with nuclear grade of 1 had the lowest mean Ki-67LI (23.18\%); highest mean Ki$67 \mathrm{LI}(40.87 \%)$ was observed in nuclear grade of 3. ER and PR positive patients had lower Ki-67LI (28.37\% and $29.56 \%$, respectively), whereas P53 and HER-2 positive patients had higher Ki-67LI (36.27\% and 35.45\%, respectively) (Table-1).

Considering normal distribution of tumor size, number of involved lymph nodes, age, histological grade, nuclear grade, ER, PR, P53 and HER-2, we used simple linear regression model and Pearson correlation coefficient to evaluate their associations with Ki-67 LI. Table-2 shows the results of linear regression model; from selected variables tumor size and histological grade showed no significant correlation with $\mathrm{Ki}-67 \mathrm{LI}(\mathrm{P}=0.195$ and $\mathrm{P}=0.721$, respectively). Age, ER and PR had inverse associations with Ki-67LI expression. $(\mathrm{P}<0.05)$
Table 1. Correlation of the mean ki-76 with clinicopathological features and the biomarkers in the pathologic specimens

\begin{tabular}{|c|c|c|}
\hline $\begin{array}{l}\text { Age groups } \\
\text { (years) }\end{array}$ & $\mathbf{N}(\%)$ & $\begin{array}{c}\text { Mean Ki- } \\
\text { 67LI(\%) }\end{array}$ \\
\hline $18-30$ & $5(0.97)$ & $32 \pm 4.47$ \\
\hline $30-40$ & $67(13.06)$ & $34.17 \pm 13.88$ \\
\hline $40-50$ & $162(31.58)$ & $33.31 \pm 14.3$ \\
\hline $50-60$ & $153(29.82)$ & $32.24 \pm 14.7$ \\
\hline $60-70$ & $86(16.76)$ & $27.22 \pm 12.37$ \\
\hline Older than 70 & $40(7.80)$ & $27.55 \pm 11.74$ \\
\hline \multicolumn{3}{|l|}{ Tumor size (cm) } \\
\hline lower than 1 & $29(5.65)$ & $27.93 \pm 13.72$ \\
\hline $1-3$ & $330(64.33)$ & $31.89 \pm 14.06$ \\
\hline $3-5$ & $105(20.47)$ & $31.78 \pm 13.12$ \\
\hline $5-7$ & $21(4.09)$ & $35.09 \pm 13.04$ \\
\hline Higher than 7 & $15(2.92)$ & $33.33 \pm 17.38$ \\
\hline Not reported & $13(2.53)$ & $24.15 \pm 15.74$ \\
\hline \multicolumn{3}{|c|}{ Lymph nodes involved } \\
\hline 0 & $188(36.65)$ & $29.80 \pm 14.33$ \\
\hline $1-3$ & $124(24.17)$ & $29.65 \pm 13.36$ \\
\hline $4-6$ & $65(12.67)$ & $32.64 \pm 13.89$ \\
\hline $7-9$ & $32(6.24)$ & $37.81 \pm 14.18$ \\
\hline $10-12$ & $14(2.73)$ & $34.64 \pm 13.51$ \\
\hline $13-15$ & $42(8.19)$ & $34.64 \pm 12.26$ \\
\hline More than 16 & $33(6.43)$ & $33.94 \pm 14.93$ \\
\hline Not reported & $15(2.92)$ & $36.67 \pm 12.48$ \\
\hline \multicolumn{3}{|c|}{ Histologic grade } \\
\hline 1 & $18(3.51)$ & $17.78 \pm 9.27$ \\
\hline 1.5 & $19(3.7)$ & $26.74 \pm 10.11$ \\
\hline 2 & $280(54.58)$ & $31 \pm 13.39$ \\
\hline 2.5 & $22(4.29)$ & $32.81 \pm 14.3$ \\
\hline 3 & $129(25.15)$ & $36.52 \pm 14.79$ \\
\hline Not reported & $45(8.77)$ & $28.49 \pm 12.67$ \\
\hline \multicolumn{3}{|l|}{ Nuclear grade } \\
\hline 0 & $328(63.94)$ & $31.12 \pm 14.2$ \\
\hline 1 & $11(2.14)$ & $23.18 \pm 10.06$ \\
\hline 1.5 & $23(4.48)$ & $25.56 \pm 9.63$ \\
\hline 2 & $81(15.79)$ & $30.64 \pm 12.91$ \\
\hline 2.5 & $24(4.68)$ & $33.75 \pm 13.29$ \\
\hline 3 & $46(8.97)$ & $40.87 \pm 13.34$ \\
\hline \multicolumn{3}{|c|}{ Estrogen receptor } \\
\hline Negative & $123(23.98)$ & $41.92 \pm 13.27$ \\
\hline Positive & $390(76.02)$ & $28.37 \pm 12.58$ \\
\hline
\end{tabular}

Continues in next page 


\begin{tabular}{lcc}
\hline \multicolumn{3}{l}{ Progesterone receptor } \\
\hline Negative & $166(32.36)$ & $39.71 \pm 14.11$ \\
Positive & $347(67.64)$ & $27.75 \pm 12.18$ \\
\hline P53 & \\
\hline Negative & $355(69.20)$ & $29.56 \pm 13.88$ \\
Positive & $155(30.21)$ & $36.27 \pm 13.26$ \\
Not reported & $3(0.58)$ & $35 \pm 8.66$ \\
\hline Human epidermal growth factor receptor-2 \\
\hline Negative & $300(58.48)$ & $28.9 \pm 14.1$ \\
Positive & $213(41.52)$ & $35.45 \pm 12.94$ \\
\hline
\end{tabular}

On the other hand, number of lymph nodes involved, HER-2, P53 and nuclear grade had positive correlation with $\mathrm{Ki}-67 \mathrm{LI}(\mathrm{P}<0.05)$

\section{Discussion}

Despite recent progresses in molecular biology, available treatments and screening program, breast cancer remains the most common cancer and the leading cause of cancer-related deaths in females [9]. Many molecular markers are recognizable in breast cancer which play roles in cancer diagnosis, prognosis or treatment response. Ki-67, discovered by Gredes et al. [11], has prognostic and predictive values in breast cancer.

In this study, we tried to express the relationship between Ki-67 and other markers used in breast cancer including age, tumor size, lymph node involvement, nuclear and histological grades, ER, PR and HER-2 in 513 female breast cancer patients. Ki-67 showed significant correlation with lymph node involvement, HER-2 and nuclear grade. Furthermore, it was inversely associated with age, ER and PR expression.

Many other studies sought the association between Ki-67 and other markers; Shapochka et al. revealed a direct correlation between Ki-67 and tumor grade and no association between Ki-67 and age or tumor size [8]. These results were similar to another study that found tumors with high Ki-67 had statistically higher mitotic rate, nuclear and histological grades and no significant relation was between Ki-
67 and age at diagnosis, menopausal status, tumor size and lymph node metastases [24]. On the contrary, Sahin et al. found a strong correlation between Ki-67 staining percentage and age in addition to correlation with nuclear grade, mitotic rate and 5-year disease free and overall survivals [25]. Moreover, a study of 203 female breast cancer patients revealed that Ki-67 statistically correlated with tumor size and nuclear estrogen receptor content, and premenopausal women had greater $\mathrm{Ki}-67$ values (median value, $14.1 \%$ ) than postmenopausal ones (median value, 9.8\%). Similar to Veronese et al. and Crispino studies, no correlation with lymph node involvement was found $[24,26]$. Interestingly, a study in Iran demonstrated significant association between axillary lymph node involvement and level of Ki-67 [12].

P53 is another tumor marker and prognostic factor used in breast cancer; several studies tried to find the associations between P53 and other markers including Ki-67 as well as comparing them to find the superior prognostic factor. A study on 71 primary breast carcinoma specimens revealed that p53 protein was associated with high levels of Ki-67 and lymph-node status [27]. Ki-67 was correlated with high mitotic count, histologic grade, negative progesterone receptor status and P53 expression in another study done on 97 breast carcinomas [27]. Li et al. studied 151 cases of breast cancer and found that Ki-67 did not relate to age, tumor size and lymph node status, whereas it correlated with tumor stage and P53 expression [28]. Two studies in Iran compared the prognostic value of P53 with $\mathrm{Ki}-67$ in breast cancer and achieved contradictory results $[29,30]$. The study in western Iran showed that the hazard ratios for P53 and Ki-67 were 1.37 and 0.52 , respectively. Thus, P53 is more important than Ki-67 on survival rate [29]. Another study in eastern Iran demonstrated that Ki-67 had significant relationship with the survival rate, but over-expression of P53 did not show such a significance. Hence, they concluded that Ki-67 marker is more important than $\mathrm{P} 53$ protein in breast cancer prognosis [30]. 
Table 2. Correlation Between Selected Variables and Ki-67 Using Simple Linear Regression

\begin{tabular}{|c|c|c|c|c|c|}
\hline \multirow{2}{*}{ Variable } & \multirow{2}{*}{$\mathbf{B}^{1}$} & \multicolumn{2}{|c|}{ 95\% Confidence interval } & \multirow{2}{*}{$\begin{array}{l}\text { Standard } \\
\text { deviation }\end{array}$} & \multirow{2}{*}{ P-value } \\
\hline & & Lower & Upper & & \\
\hline Age & -0.150 & 1.74 & 3.66 & 0.078 & 0.057 \\
\hline Tumor size & -0.818 & 1.34 & 5.26 & 0.629 & 0.195 \\
\hline $\begin{array}{l}\text { Lymph nodes } \\
\text { involvement }\end{array}$ & 0.231 & 1.64. & 3.14 & 0.087 & 0.008 \\
\hline ER & -9.032 & -5.34 & 2.93 & 2.291 & 0.001 \\
\hline PR & -3.951 & -2.92 & 2.12 & 2.082 & 0.058 \\
\hline HER-2 & 3.282 & 1.88 & 8.92 & 1.193 & 0.006 \\
\hline P53 & 3.878 & 1.43 & 2.49 & 1.244 & 0.002 \\
\hline Histological grade & 0.855 & -4.16 & 6.16 & 2.293 & 0.721 \\
\hline Nuclear Grade & 6.117 & 2.84 & 9.16 & 2.182 & 0.006 \\
\hline
\end{tabular}

'B: regression coefficient for dependent variable

ER: Estrogen receptor, PR: Progesterone receptor, HER-2: Human epidermal growth factor receptor-2

\section{Conclusion}

Despite similar results regarding Ki-67 correlation with tumor grade, P53, ER and PR there is still no uniform opinion in terms of Ki-67 association with other clinical characteristics such as age, tumor size or lymph node involvement. These results vary due to different types of studied breast cancer samples or sample size population characteristics, and a consonant conclusion may never be found in general population. What is most certain about Ki-67 is its role in breast cancer prognosis, and future studies should focus more on finding other functional values for Ki-67 such as treatment prediction and cancer drug therapy.

\section{Conflict of Interest}

The authors declare that they have no conflicts of interest.

\section{References}

1. Mirmalek SA, Hajilou M, Salimi

Tabatabaee SA, Parsa Y, Yadollah-

Damavandi S, Parsa T. Prevalence of

HER-2 and Hormone Receptors and P53

Mutations in the Pathologic Specimens

of Breast Cancer Patients. Int J Breast

Cancer. 2014; 2014: 564308.

2. Mirmalek SA, Azizi MA, Jangholi E, Yadollah-Damavandi S, Javidi MA,

Parsa $\mathrm{Y}$ et al. Cytotoxic and apoptogenic effect of hypericin, the bioactive component of Hypericum perforatum on the MCF-7 human breast cancer cell line. Cancer Cell Int. 2015; 16: 3.

3. Mirmalek S, Jangholi E, Jafari M,
Yadollah-Damavandi S, Javidi M, Parsa $\mathrm{Y}$ et al. Comparison of in Vitro Cytotoxicity and Apoptogenic Activity of Magnesium Chloride and Cisplatin as Conventional Chemotherapeutic Agents in the MCF-7 Cell Line. Asian Pac J Cancer Prev. 2016;17 Spec No.:131-4.

4. Kogevinas M, Cancer IAfRo. Social inequalities and cancer: International Agency for Research on Cancer Lyon, France; 1997.

5. Parsa Y, Mirmalek SA, Elham Kani F, Aidun A, Salimi-Tabatabaee SA, Yadollah-Damavandi S, et al. A Review of the Clinical Implications of Breast 
Cancer Biology. Electronic Physician. 2016; 8(5):2416-24.

6. Ebrahimi M, Vahdaninia M, Montazeri

A. Risk factors for breast cancer in Iran: a case-control study. Breast cancer research. 2002;4(5):R10.

7. Movahedi M, Haghighat $\mathrm{S}$, Khayamzadeh M, Moradi A, GhanbariMotlagh A, Mirzaei H, et al. Survival rate of breast cancer based on geographical variation in iran, a national study. Iranian Red Crescent medical journal. 2012;14(12):798-804.

8. Shapochka DO, Zaletok SP, Gnidyuk MI. Relationship between NF-kappaB, ER, PR, Her2/neu, Ki67, p53 expression in human breast cancer. Experimental oncology. 2012;34(4):358-63.

9. Mirmalek SA, Hajilou M, Salimi Tabatabaee SA, Parsa Y, YadollahDamavandi S, Parsa T. Prevalence of HER-2 and Hormone Receptors and P53 Mutations in the Pathologic Specimens of Breast Cancer Patients. Int J Breast Cancer. 2014; 2014: 564308.

10. Mirmalek SA, Elhamkani F, Tabatabaee SAS, Mahmoodzadeh H, Parsa Y, Yadollah-Damavandi S, et al. Introduction of HER-2 and a Short Review on Its Role in Prognosis and Treatment of Breast Cancer. GMJ. 2014;3(3):132-44.

11. Gerdes J, Schwab U, Lemke H, Stein H. Production of a mouse monoclonal antibody reactive with a human nuclear antigen associated with cell proliferation. International journal of cancer Journal international du cancer. 1983;31(1):1320.

12. Rahmanzadeh R, Huttmann G, Gerdes J, Scholzen T. Chromophore-assisted light inactivation of pKi-67 leads to inhibition of ribosomal RNA synthesis. Cell proliferation. 2007;40(3):422-30.

13. Beresford MJ, Wilson GD, Makris A. Measuring proliferation in breast cancer: practicalities and applications. Breast cancer research : BCR. 2006;8(6):216.

14. Lopez F, Belloc F, Lacombe F, Dumain $\mathrm{P}$, Reiffers J, Bernard P, et al. Modalities of synthesis of Ki67 antigen during the stimulation of lymphocytes. Cytometry. 1991;12(1):42-9.

15. Abdsaleh S, Wärnberg F, Azavedo E, Lindgren P, Amini RM. Comparison of core needle biopsy and surgical specimens in malignant breast lesions regarding histological features and hormone receptor expression. Histopathology. 2008;52(6):773-5.

16. Trihia H, Murray S, Price K, Gelber RD, Golouh R, Goldhirsch A, et al. Ki67 expression in breast carcinoma. Cancer. 2003;97(5):1321-31.

17. Weidner N, Moore II DH, Vartanian R. Correlation of Ki-67 antigen expression with mitotic figure index and tumor grade in breast carcinomas using the novel "paraffin"-reactive MIB1 antibody. Human pathology. 1994;25(4):337-42.

18. Yerushalmi R, Woods R, Ravdin PM, Hayes MM, Gelmon KA. Ki67 in breast cancer: prognostic and predictive potential. The Lancet Oncology. 2010;11(2):174-83.

19. Nishimura R, Osako T, Okumura Y, Hayashi M, Toyozumi Y, Arima N. Ki67 as a prognostic marker according to breast cancer subtype and a predictor of recurrence time in primary breast cancer. Experimental and therapeutic medicine. 2010;1(5):747-54.

20. de Azambuja E, Cardoso F, de Castro G, Jr., Colozza M, Mano MS, Durbecq $\mathrm{V}$, et al. Ki-67 as prognostic marker in early breast cancer: a meta-analysis of published studies involving 12,155 patients. British journal of cancer. 2007;96(10):1504-13.

21. Keam B, Im S-A, Lee K-H, Han S-W, Oh D-Y, Kim JH, et al. Ki-67 can be used for further classification of triple negative breast cancer into two subtypes with different response and prognosis. Breast cancer research : BCR. 2011;13(2):R22.

22. Fasching PA, Heusinger K, Haeberle L, Niklos M, Hein A, Bayer CM, et al. Ki67, chemotherapy response, and prognosis in breast cancer patients receiving neoadjuvant treatment. BMC cancer. 2011;11(1):486.

23. Aleskandarany MA, Green AR, 
Benhasouna AA, Barros FF, Neal K, Reis-Filho JS et al. Prognostic value of proliferation assay in the luminal, HER2positive, and triple-negative biologic classes of breast cancer. Breast Cancer Research. 2012;14(1):1-11.

24. Crispino S, Brenna A, Colombo D, Flores B, D'Amico S, Lissoni P, et al. Ki-67 labeling index in breast cancer. Tumori. 1989;75(6):557-62.

25. Sahin AA, Ro JY, El-Naggar AK, Ordonez NG, Ayala AG, Ro J, et al. Ki67 immunostaining in node-negative stage I/II breast carcinoma. Significant correlation with prognosis. Cancer. 1991;68(3):549-57.

26. Veronese S, Gambacorta M. Detection of $\mathrm{Ki}-67$ proliferation rate in breast cancer. Correlation with clinical and pathologic features. American journal of clinical pathology. 1991;95(1):30-4.

27. Midulla C, De Iorio P, Nagar C, Pisani T, Cenci M, Valli C, et al. Immunohistochemical expression of p53, nm23-HI, Ki67 and DNA ploidy: correlation with lymph node status and other clinical pathologic parameters in breast cancer. Anticancer research. 1998;19(5B):4033-7.

28. Li B, Zhu Z, Wang J, Hou J, Zhao J, Zhang P, et al. [Expression correlation of Ki67 to P53, VEGF, and C-erbB-2 genes in breast cancer and their clinical significances]. Ai zheng= Aizheng $=$ Chinese journal of cancer. 2004;23(10):1176-9.

29. Payandeh M, Sadeghi M, Fekri A, Sadeghi E. P53 mutation compared with Ki67 marker in metastasis of breast cancer in western Iran. Journal of Solid Tumors. 2014;4(3):p4.

30. Golmohammadi R, Pejhan A. The prognostic value of the P53 protein and the Ki67 marker in breast cancer patients. JPMA The Journal of the Pakistan Medical Association. 2012;62(9):871-5. 